\title{
Two approaches for enhancing the hydrogenation properties of palladium: Metal nanoparticle and thin film over layers ${ }^{\dagger}$
}

\author{
MANIKA KHANUJA ${ }^{1}$, B R MEHTA ${ }^{1, *}$ and S M SHIVAPRASAD ${ }^{2}$ \\ ${ }^{1}$ Thin Film Laboratory, Department of Physics, Indian Institute of Technology Delhi, New Delhi 110016 \\ ${ }^{2}$ Chemistry and Physics of Materials Unit, Jawaharlal Nehru Centre for Advanced Scientific Research \\ (JNCASR,) Jakkur PO, Bangalore 560064 \\ e-mail: brmehta $@$ physics.iitd.ernet.in
}

\begin{abstract}
In the present study, two approaches have been used for enhancing the hydrogenation properties of $\mathrm{Pd}$. In the first approach, metal thin film $(\mathrm{Cu}, \mathrm{Ag})$ has been deposited over Pd and hydrogenation properties of bimetal layer $\mathrm{Cu}$ (thin film)/Pd(thin film) and $\mathrm{Ag}$ (thin film)/Pd(thin film) have been studied. In the second approach, Ag metal nanoparticles have been deposited over Pd and hydrogenation properties of $\mathrm{Ag}$ (nanoparticle)/Pd (thin film) have been studied and compared with $\mathrm{Ag}($ thin film)/Pd(thin film) bimetal layer system. The observed hydrogen sensing response is stable and reversible over a number of hydrogen loading and deloading cycles in both bimetallic systems. Alloying between Ag and Pd is suppressed in case of $\mathrm{Ag}$ (nanoparticle)/ $\mathrm{Pd}$ (thin film) bimetallic layer on annealing as compared to $\mathrm{Ag}$ (thin film)/Pd(thin film).
\end{abstract}

Keywords. $\mathrm{Cu} / \mathrm{Pd}$ bimetal layers; $\mathrm{Ag} / \mathrm{Pd}$ bimetal layers; nanoparticles; hydrogen sensing; XPS; GAXRD.

\section{Introduction}

Palladium has several important roles in hydrogen economy, it is used to generate, purify, store and detect hydrogen. ${ }^{1-4}$ A multitude of industries use hydrogen as an integral part of the process. ${ }^{5,6}$ Hydrogen is highly flammable at concentration $>4 \%{ }^{1}$ Being lightest, it disperses rapidly due to low mass and high diffusivity. ${ }^{1,2}$ Palladium is chemically selective towards $\mathrm{H}_{2}$ with a reversible and rapid hydrogen sensing response with high sensitivity. ${ }^{1} \mathrm{Pd}-\mathrm{H}$ is a two phase system with $\alpha$ (low hydrogen concentration $\mathrm{H} / \mathrm{Pd} \leq 0.025$ to 0.03 atomic $\%$ at $\sim 298 \mathrm{~K}$ ) and $\beta$ (high hydrogen concentration $\mathrm{H} / \mathrm{Pd} \geq 0.06$ atomic $\%$ at $\sim 298 \mathrm{~K})$ phases $(0.03 \leq \mathrm{Pd} / \mathrm{H} \leq 0.06$ two phase $\alpha+\beta$ region). ${ }^{1}$ This phase transformation from $\alpha$ to $\beta$ is accompanied by an expansion of the lattice by about $4 \%$ which is responsible for mechanical instability in Pd. ${ }^{1}$ Pure Pd membrane, however, would be destroyed due to hydrogen embrittlement when it was used at temperatures below $573 \mathrm{~K}$ and hydrogen pressures above $2 \mathrm{MPa}^{7}$ Sulphur containing gases like $\mathrm{H}_{2} \mathrm{~S}$ and $\mathrm{SO}_{2}$ poison $\mathrm{Pd}$ by forming sulphur deposits on its surface. ${ }^{8-10}$ The poisoning of Pd with

\footnotetext{
${ }^{\dagger}$ Dedicated to Prof. C N R Rao on his 75th birthday

*For correspondence
}

these gases is irreversible. As a result, Pd based hydrogen sensors lose sensitivity to $\mathrm{H}_{2}$ and have significantly slower response times. 'Nanoparticle route' and 'bimetal layer route' have been employed to maximize the $\mathrm{Pd}-\mathrm{H}$ interaction and to overcome the above mentioned shortcomings. ${ }^{11,12}$ In a bimetallic system, properties of two elements are combined in a synergic manner to yield a surface which is more reactive than either of the two. ${ }^{12,13}$ Alloying of Pd with $\mathrm{Ni}, \mathrm{Cu}, \mathrm{Ag}$ or $\mathrm{Au}$ enhances the single phase $\alpha$ region. ${ }^{14}$ Firstly, the critical temperature of miscibility gap for the $\alpha$ to $\beta$ phase transition is lowered in $\mathrm{Pd}$ alloys. This helps in enhancing their mechanical properties and withstanding repeated temperature cycling. Secondly, hydrogen permeability of many alloys including $\mathrm{PdAg}_{23}, \mathrm{PdCu}_{40}, \mathrm{PdY}_{7}$ and $\mathrm{PdAu}_{5}$ can be improved. ${ }^{15-17}$ In the present work, H-Pd interaction in $\mathrm{Cu} / \mathrm{Pd}$ and $\mathrm{Ag} / \mathrm{Pd}$ bimetallic layers has been investigated by studying the resistance change on hydrogen loading and deloading. Structural and electronic properties of as-deposited and annealed $\mathrm{Cu} / \mathrm{Pd}$ and $\mathrm{Ag} / \mathrm{Pd}$ bimetal layers have been studied.

\section{Experimental}

$\mathrm{Cu} / \mathrm{Pd}$ and $\mathrm{Ag} / \mathrm{Pd}$ bimetal layers were deposited using sequential vacuum deposition at a base pressure 
of $1 \times 10^{-6}$ Torr onto a glass substrate. Film thickness is determined by measuring the frequency shift in a quartz crystal oscillator, which is proportional to the deposited mass and thus will be referred to as 'mass thickness'. The thickness of the Pd film was maintained at $100 \AA$ using a quartz crystal monitor. $\mathrm{Cu}$ or Ag layers of $20 \AA$ thickness were deposited onto the $\mathrm{Pd}$ films by evaporating high purity $\mathrm{Cu}$ or $\mathrm{Ag}$ at $1 \times 10^{-6}$ Torr to form $\mathrm{Cu} / \mathrm{Pd}$ and $\mathrm{Ag} / \mathrm{Pd}$ bimetal layer structures, respectively. Ag nanoparticles of effective mass thickness $10 \mathrm{~nm}$ have been deposited onto Pd thin film using inert gas deposition technique at argon pressure of $5 \times 10^{-4}$ Torr. The samples were loaded with hydrogen via gas phase loading. For measuring electrical resistivity in hydrogen, in situ electrical measurements were carried out by the four previously deposited aluminum (Al) contacts on glass substrates. For deloading, chamber was evacuated using a mechanical rotary pump. Keithley 224 programmable current source and Keithley 6517A electrometer resistance meter were used during electrical measurements. Structural analysis of the films was done with the help of Philips 'XPert' model glancing angle X-ray diffractometer (GAXRD). XPS measurements were performed in an ultra-high vacuum chamber (PHI 1257) at a base pressure of $5.3 \times 10^{-8} \mathrm{~Pa}$. The XPS spectrometer is equipped with a high-resolution hemispherical electron analyser (279.4 mm diameter with $25 \mathrm{meV}$ resolution) and $\mathrm{AlK}_{\alpha}(h v=1486.6 \mathrm{eV}) \mathrm{X}$-ray anode as the photon source.

\section{Results and discussion}

\section{$3.1 \mathrm{Cu}$ (thin film)/Pd(thin film) bimetal layers}

Hydrogen-sensing response of $\mathrm{Cu}$ (thin film)/Pd (thin film) bimetal structure is shown in figure 1. Stable and reversible hydrogen sensing response is observed over a number of hydrogen loading and deloading cycles. On hydrogen loading, resistance of bimetal layer increases by about $7.4 \%$. This is because $\mathrm{Pd}$ on interaction with hydrogen forms palladium hydride whose resistance is higher than that of $\mathrm{Pd}$. Hydrogen sensing response of annealed $\mathrm{Cu} / \mathrm{Pd}$ bimetal layer is shown in figure 2 . The sensing response decreases in annealed (up to $300^{\circ} \mathrm{C}$ ) $\mathrm{Cu} / \mathrm{Pd}$ bimetal layers. Percentage change in resistance was observed to be $5.3 \%, 4.2 \%$ and $1.3 \%$ in $100^{\circ} \mathrm{C}$, $200^{\circ} \mathrm{C}$ and $300^{\circ} \mathrm{C}$ annealed $\mathrm{Cu} / \mathrm{Pd}$ bimetal layers, respectively. However, hydrogen sensing response is higher in $400^{\circ} \mathrm{C}$ annealed samples. In $350^{\circ} \mathrm{C}, 400^{\circ} \mathrm{C}$ and $4500^{\circ} \mathrm{C}$, resistance change is $3.2 \%, 6.6 \%$ and $7.2 \%$ respectively. As shown in figure 2 , from point A to $\mathrm{B}$, resistance change decreases and from $\mathrm{B}$ to $\mathrm{C}$, resistance change increases.

To explain the hydrogen sensing response in terms of electronic and geometric changes that occur during annealing, surface sensitive x-ray photoelectron spectroscopy (XPS) and glancing angle X-ray diffraction (GAXRD) studies have been done. ${ }^{18}$ The XPS features of core-electron and valence band (VB) spectra have been recorded for $\mathrm{Cu} / \mathrm{Pd}$ bimetal

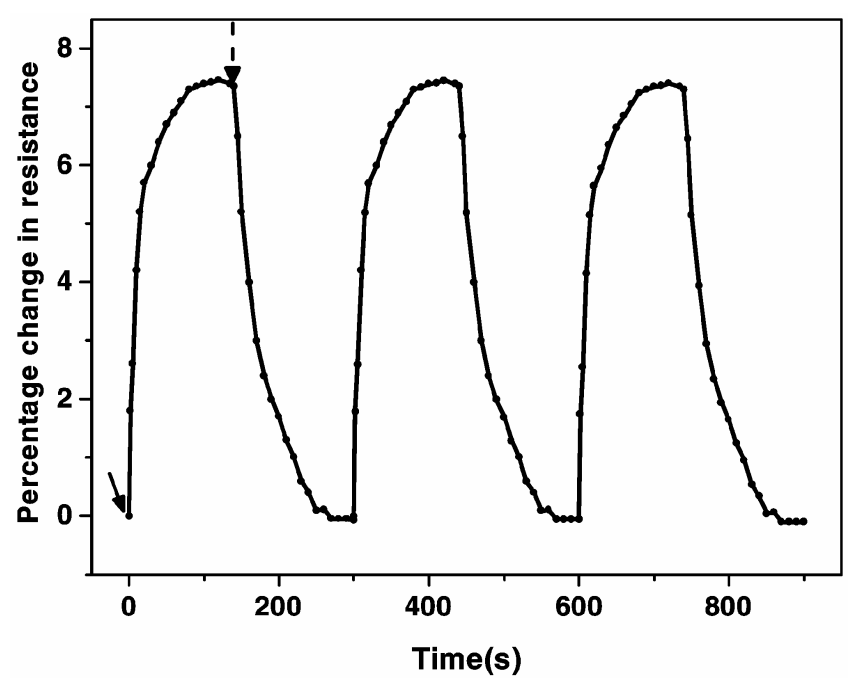

Figure 1. Stable and reversible hydrogen sensing response of $\mathrm{Cu} / \mathrm{Pd}$ bimetal layers. Solid and dotted arrows show loading and deloading points.

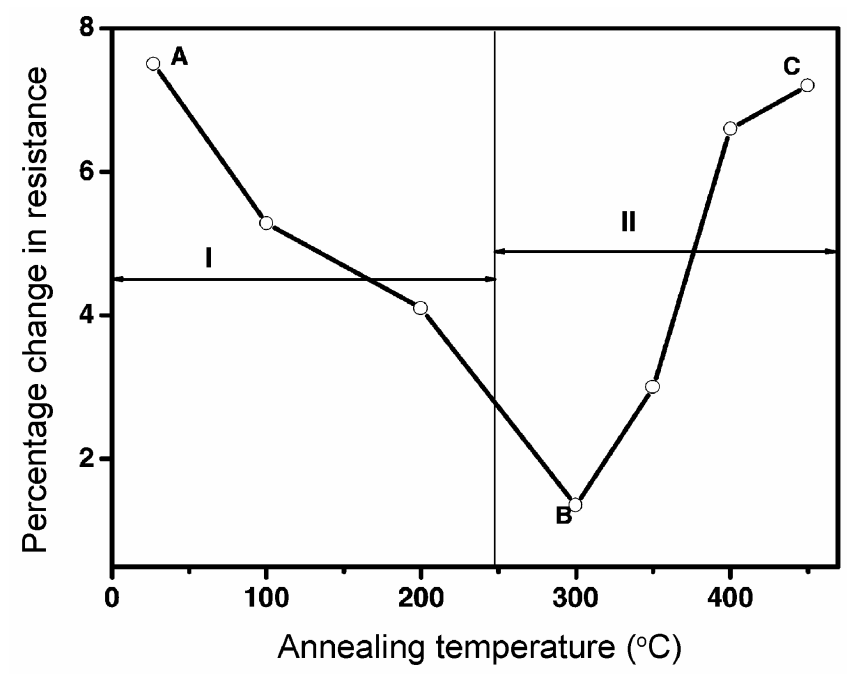

Figure 2. Hydrogen sensing response of $\mathrm{Cu} / \mathrm{Pd}$ bimetal layer at $100 \% \mathrm{H}_{2}$ concentration and at different annealing temperatures. 
layer samples. The intensity of the $\mathrm{Pd}\left(3 d_{5 / 2}\right)$ and $\mathrm{Cu}$ $\left(2 p_{3 / 2}\right)$ XPS core lines was monitored as a function of annealing at different temperatures. It was observed that concentration (intensity ratio: $\mathrm{Pd} 3 d_{5 / 2} /$ $\mathrm{Cu} 2 p_{3 / 2}$ ) composition- profile as a function of temperature can be divided into two regions as shown in figure 3 . In the first region (up to $250^{\circ} \mathrm{C}$ ), $\mathrm{Pd}$ signal increases whereas $\mathrm{Cu}$ signal decreases due to $\mathrm{Pd}-\mathrm{Cu}$ interdiffusion. In the second region $\left(250^{\circ} \mathrm{C}-600^{\circ} \mathrm{C}\right)$, $\mathrm{Pd}$ and $\mathrm{Cu}$ peak attains a constant value. This region represents $\mathrm{Pd}-\mathrm{Cu}$ surface alloy formation. Thus with increasing annealing temperature, intermixing occurs between $\mathrm{Cu}$ and $\mathrm{Pd}$ and a surface alloy is formed at intermediate temperature region. Hydrogen sensing has been observed in temperature range corresponding to regions I and II. Figure 4 shows the $\mathrm{Pd}\left(3 d_{5 / 2}\right)$ core-level spectra of as-deposited and $400^{\circ} \mathrm{C}$ annealed sample. In sample, annealed at $400^{\circ} \mathrm{C}$, there is a clear presence of two Pd peaks. Peak Pd (A) at higher binding energy $337.1 \mathrm{eV}$ is due to alloyed $\mathrm{Pd}$ atoms and peak $\mathrm{Pd}(\mathrm{M})$ at $335.6 \mathrm{eV}$ is due to metallic Pd atoms. The observed core-level shift is due to charge transfer from $\mathrm{Pd}$ to $\mathrm{Cu}$. $\mathrm{Cu}$ has a $4 s$ conduction band that is only half filled whereas Pd has an almost filled $4 d$ valence band. There is a flow of electrons towards the element with the larger fraction of empty states in the valence band. ${ }^{12}$ With increasing annealing temperature, area under the alloyed Pd component Pd (A) was observed to increase, whereas that of metallic component Pd (M) keeps on decreasing.

X-ray diffractograms of as-deposited and $400^{\circ} \mathrm{C}$ annealed $\mathrm{Cu} / \mathrm{Pd}$ bimetal layers are shown in figure 5 .

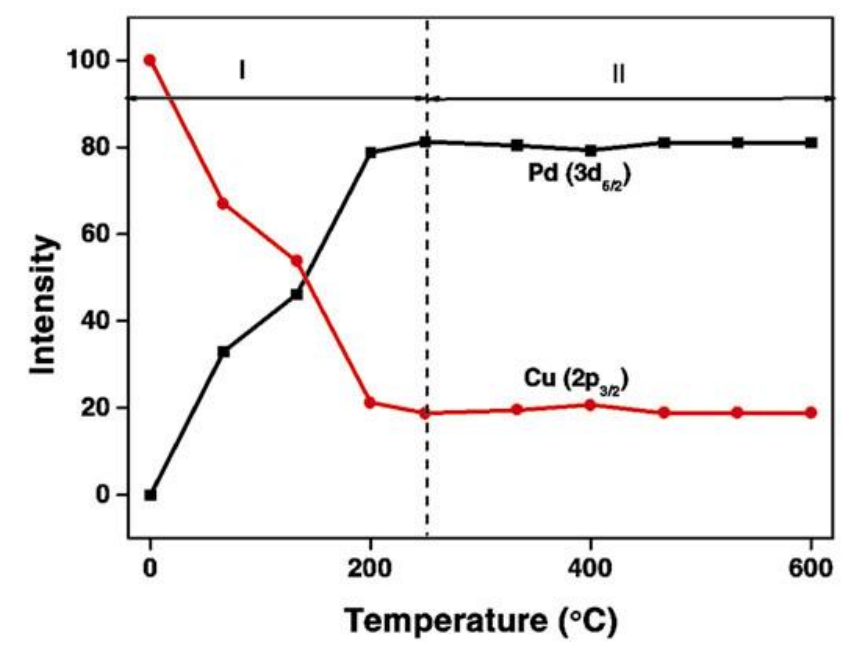

Figure 3. Area of $\mathrm{Pd}\left(3 d_{5 / 2}\right)$ and $\mathrm{Cu}\left(2 p_{3 / 2}\right)$ core level peaks as a function of annealing temperature. Regions I and II corresponding to figure 2 are also shown.
In as deposited $\mathrm{Cu}$ (thin film)/Pd(thin film) bimetal layer, there are clear and well separated (111), (200), (220) $\mathrm{Cu}$ and Pd peaks. On annealing, Pd (111) and $\mathrm{Cu}$ (111), $\mathrm{Pd}(200)$ and $\mathrm{Cu}(200)$ peaks merge and form $\mathrm{Cu}-\mathrm{Pd}(111)$ and $\mathrm{Cu}-\mathrm{Pd}(200)$ peaks. With increased annealing, $d$-values in between to that of $\mathrm{Pd}$ and $\mathrm{Cu}$ standard ASTM values are attained. The $d$ value for $\mathrm{Pd}(111)$ and $\mathrm{Cu}(111)$ are $2.25 \AA$ and $2.09 \AA$ respectively. For sample annealed at $400^{\circ} \mathrm{C}$, $d(111)=2.21 \AA$. Thus, in case of annealed sample, $d$ value lies in between those of pure palladium and copper confirming the surface alloy formation. ${ }^{18}$ The $d$-value for the (200) and (220) planes also supports the above observation.

In $\mathrm{Cu}$ (thin film)/Pd (thin film) bimetal layer system, valence band (VB) spectra can be divided into three regions; (1) Pd dominance at lower B.E; (2) $\mathrm{Cu}$ dominance at higher B.E; (3) intermediate region formed by overlapping of $\mathrm{Pd} 4 d$ and $\mathrm{Cu} 3 d .{ }^{19}$ Third region dominates on annealing as formation of new states take place due to the enhanced overlapping of $\mathrm{Pd} 4 d$ and $\mathrm{Cu} 3 d$ bands. In as-deposited $\mathrm{Cu} / \mathrm{Pd}$ bimetal layer, two effects come into play; (1) electronic effect or ligand effect; (2) geometric effect. Electronic effect arises due to the presence of different kinds of atoms in the surrounding. In $\mathrm{Cu} / \mathrm{Pd}$ system, due to electronic effect, $\mathrm{Pd}-\mathrm{H}$ interaction decreases due to electron flow from $\mathrm{Pd}$ to $\mathrm{Cu}$. Also due to $7 \cdot 1 \%$ lattice mismatch between $\mathrm{Cu}$ and $\mathrm{Pd}$, compressive stress occurs which can also suppress the catalytic activity of Pd towards $\mathrm{H}_{2}$. However, on annealing, influence of neither electronic nor geometric effect on catalytic interaction of $\mathrm{Pd}$ with $\mathrm{H}_{2}$ is significant. $\mathrm{Cu}$ and $\mathrm{Pd}$ form common valence band whose catalytic properties are completely different from those of individual $\mathrm{Pd}$ and $\mathrm{Cu}$ metals. On alloying, compressive stress also reduces, thus catalytic interaction of $\mathrm{Cu} / \mathrm{Pd}$ bimetal layer increases. $\mathrm{Pd} / \mathrm{Cu}$ alloy has favourable properties like increased sulphur resistance, good thermal resilience and higher hydrogen permeability as compared to pure $\mathrm{Pd} .{ }^{14}$ At conditions of $\mathrm{H}_{2} \mathrm{~S}$ exposure that cause $80 \%$ reduction of the hydrogen flux through a pure palladium membrane, it has been reported that there is less than $10 \%$ reduction of the hydrogen flux through palladium-copper membrane alloy. ${ }^{15}$

\subsection{Ag(thin film)/Pd(thin film) and Ag(nanoparticle)/Pd(thin film) bimetal layers}

In $\mathrm{Ag} / \mathrm{Pd}$ bimetal layer system, the effect of converting the metal overlayer from thin film (TF) to metal 

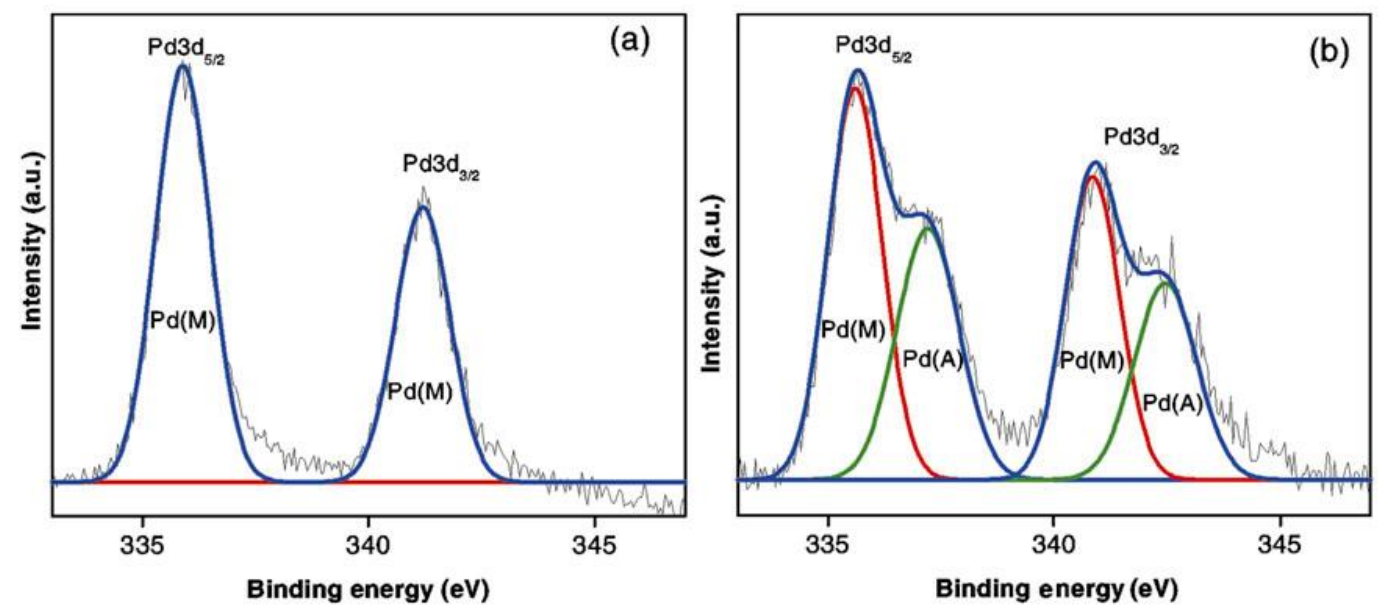

Figure 4. Core level spectra of $\mathrm{Pd}\left(3 d_{5 / 2}\right.$ and $\left.3 d_{3 / 2}\right)$ at temperatures of (a) $25^{\circ} \mathrm{C}$, (b) $400^{\circ} \mathrm{C}$, respectively. Peaks $\mathrm{Pd}(\mathrm{M})$ and $\mathrm{Pd}(\mathrm{A})$ corresponds to $\mathrm{Pd}$ metal and Pd alloy.

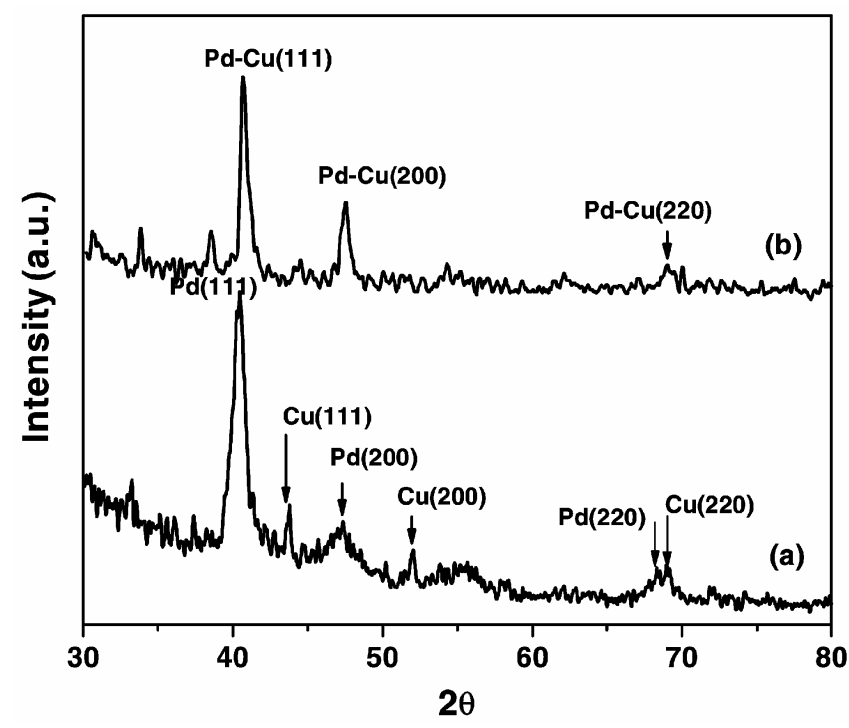

Figure 5. X-ray diffractograms of (a) as-deposited and (b) $400^{\circ} \mathrm{C}$ annealed $\mathrm{Cu} / \mathrm{Pd}$ bimetal layers.

nanoparticle (NP) layers has been investigated. Two types of samples have been studied; (1) $\mathrm{Ag}(\mathrm{TF}) /$ $\mathrm{Pd}(\mathrm{TF})$ and (2) $\mathrm{Ag}(\mathrm{NP}) / \mathrm{Pd}(\mathrm{TF})$. X-ray diffractogram of as deposited and $300^{\circ} \mathrm{C}$ annealed samples are shown in figure 6. X-ray diffractogram of as-deposited $\mathrm{Ag}(\mathrm{TF}) / \mathrm{Pd}(\mathrm{TF})$ sample show Pd (111) peak at $40.08^{\circ}$ and a small shoulder at $38.28^{\circ}$ that corresponds to Ag (111) peak. On annealing, Ag (111) and $\mathrm{Pd}$ (111) peaks merge and $\mathrm{Ag}-\mathrm{Pd}$ (111) peak occurs at $39.95^{\circ}$, whereas in $\mathrm{Ag}(\mathrm{NP}) / \mathrm{Pd}(\mathrm{TF})$ sample, peak corresponding to $\mathrm{Ag}$ is not observed. However, general XPS scan confirm the presence of $\mathrm{Ag}$ on the surface in both $\mathrm{Ag}(\mathrm{TF}) / \mathrm{Pd}(\mathrm{TF})$ and $\mathrm{Ag}(\mathrm{NP}) / \mathrm{Pd}(\mathrm{TF})$ bimetal layers. The absence of Ag (111) peak in XRD studies in $\operatorname{Ag}(\mathrm{NP}) / \mathrm{Pd}(\mathrm{TF})$ is attributed to (1) low intensity due to low mass thickness of $\mathrm{Ag}$ and (2) due to broad nature of XRD peak because of nanoparticle nature of $\mathrm{Ag}$. Position of $\mathrm{Pd}$ (111) peak remains same even after annealing. This suggests that alloy formation is suppressed in $\mathrm{Ag}(\mathrm{NP}) / \mathrm{Pd}$ (TF) nanoparticle based sample. Valence band spectra of as-deposited and $300^{\circ} \mathrm{C}$ annealed samples obtained from XPS studies are shown in figure 7. New states emerge on annealing in case of $\mathrm{Ag}(\mathrm{TF}) / \mathrm{Pd}$ (TF) sample, indicating alloying between $\mathrm{Ag}$ and $\mathrm{Pd}$. Suppression of alloy formation is also observed at $\mathrm{Gd}-\mathrm{Pd}$ interface when Gd nanoparticles are used in place of thin films. ${ }^{20}$ Thus GAXRD and XPS studies imply that alloying between $\mathrm{Ag}$ and $\mathrm{Pd}$ is suppressed in $\mathrm{Ag}(\mathrm{NP}) / \mathrm{Pd}(\mathrm{TF})$ bimetal layers.

On hydrogen loading, resistance change of about $2 \%$ and $5 \%$ is observed in $300^{\circ} \mathrm{C}$ annealed $\mathrm{Ag}(\mathrm{TF}) /$ $\mathrm{Pd}(\mathrm{TF})$ and $\operatorname{Ag}(\mathrm{NP}) / \mathrm{Pd}(\mathrm{TF})$ samples as shown in figure 8. Along with low sensitivity, large response time has been observed in $\mathrm{Ag}(\mathrm{TF}) / \mathrm{Pd}(\mathrm{TF})$ bimetal layers as compared to $\mathrm{Ag}(\mathrm{NP}) / \mathrm{Pd}(\mathrm{TF})$. Hence, alloying suppresses the hydrogen sensing response in $\operatorname{Ag}(\mathrm{TF}) / \mathrm{Pd}(\mathrm{TF})$ bimetal layer system. This is explained on the basis of d-band centroid positions of Pd and Ag. D-band centroids of these metals are quite far apart, therefore on annealing there is no common valence band formation as occurs in case of $\mathrm{Cu} / \mathrm{Pd}$ bimetal layer system. Density of states near the Fermi level also reduces on alloy formation between $\mathrm{Ag}$ 

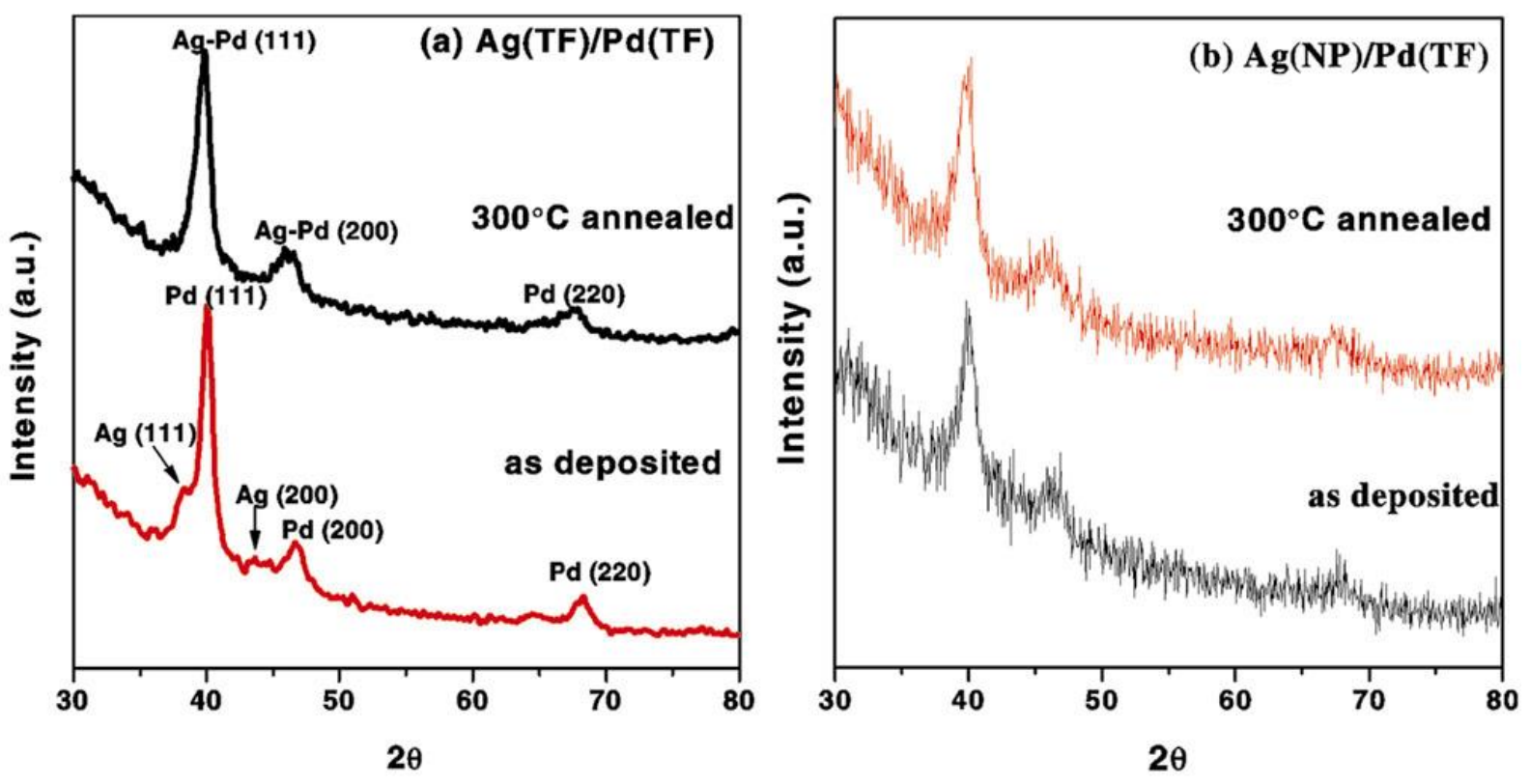

Figure 6. X-ray diffractograms of as-deposited and $300^{\circ} \mathrm{C}$ annealed (a) $\mathrm{Ag}(\mathrm{TF}) / \mathrm{Pd}(\mathrm{TF})$ and (b) $\mathrm{Ag}(\mathrm{NP}) / \mathrm{Pd}(\mathrm{TF})$ samples.
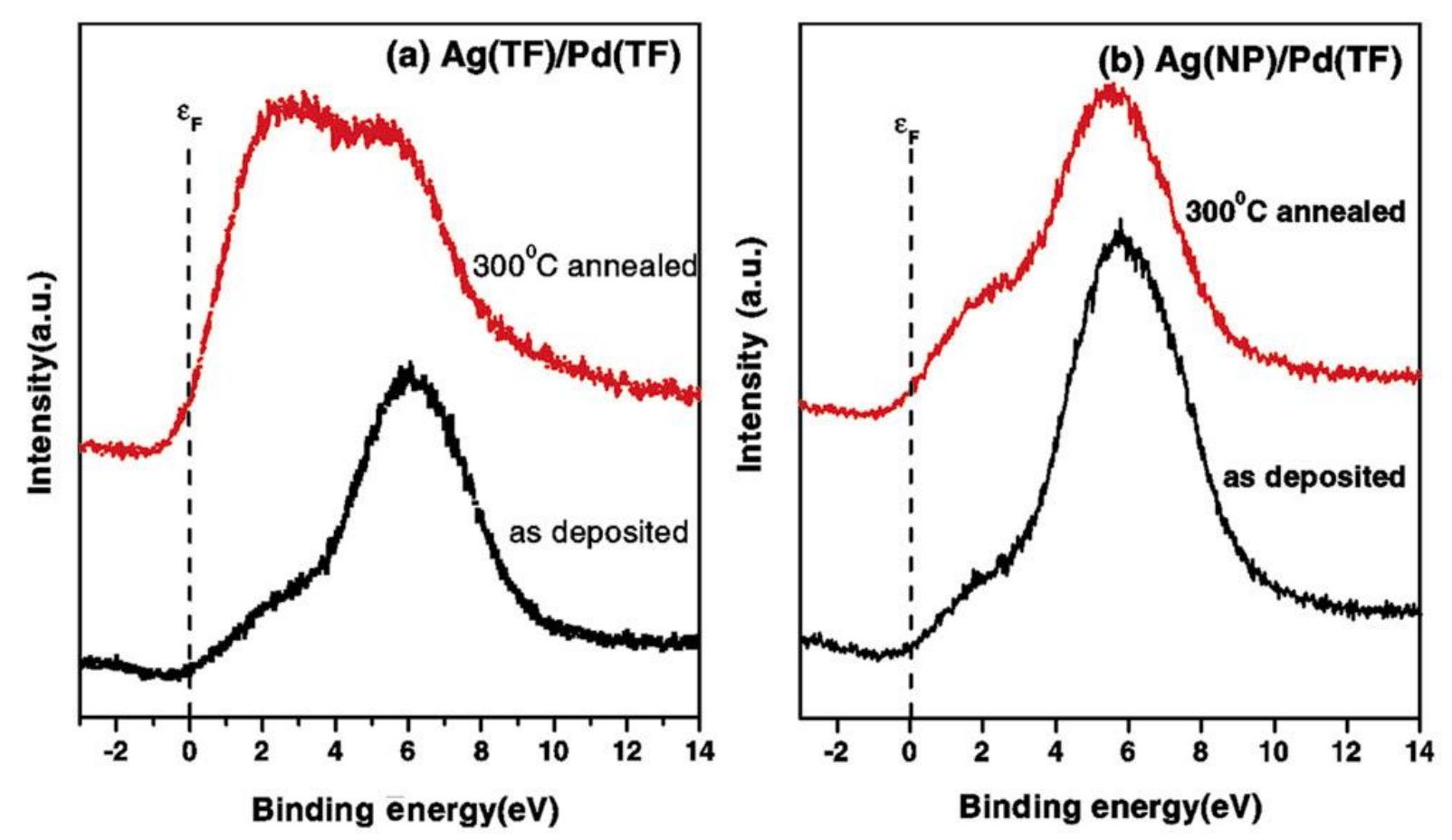

Figure 7. Valence band spectra of as-deposited and $300^{\circ} \mathrm{C}$ annealed (a) $\mathrm{Ag}(\mathrm{TF}) / \mathrm{Pd}$ and (b) $\mathrm{Ag}(\mathrm{NP}) /$ $\mathrm{Pd}(\mathrm{TF})$ samples.

and $\mathrm{Pd}^{21}$ As a result, interaction of Pd with hydrogen gets reduced on annealing due to alloy formation between $\mathrm{Ag}$ and $\mathrm{Pd}$ in $\mathrm{Ag}(\mathrm{TF}) / \mathrm{Pd}(\mathrm{TF})$ bimetal layers. This effect can be reduced by using Ag nanoparticles in place of $\mathrm{Ag}$ thin films.

\section{Conclusions}

$\mathrm{Cu} / \mathrm{Pd}$ and $\mathrm{Ag} / \mathrm{Pd}$ bimetal layers show reversible and stable hydrogen sensing response. On alloy formation, catalytic activity of $\mathrm{Pd}$ towards $\mathrm{H}_{2}$ gets en- 


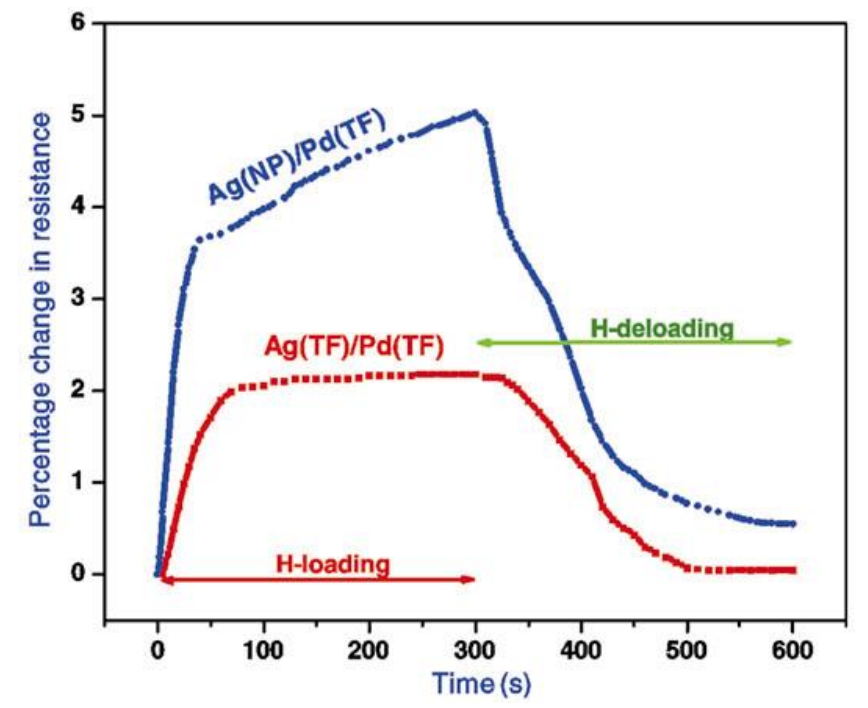

Figure 8. Hydrogen sensing response of $300^{\circ} \mathrm{C}$ annealed $\mathrm{Ag}(\mathrm{TF}) / \mathrm{Pd}(\mathrm{TF})$ and $\mathrm{Ag}(\mathrm{NP}) / \mathrm{Pd}(\mathrm{TF})$ samples.

hanced in case of $\mathrm{Cu}(\mathrm{TF}) / \mathrm{Pd}(\mathrm{TF})$ bimetal layer structures and decreases in case of $\mathrm{Ag}(\mathrm{TF}) / \mathrm{Pd}(\mathrm{TF})$ bimetal layer structures. Alloying of $\mathrm{Ag}$ with $\mathrm{Pd}$ is suppressed in case of $\mathrm{Ag}(\mathrm{NP}) / \mathrm{Pd}(\mathrm{TF})$ bimetal layers.

\section{Acknowledgement}

One of the authors (MK) thanks Council of Scientific and Industrial Research (CSIR), India for providing Senior Research Fellowship.

\section{References}

1. Lewis F A 1967 The palladium-hydrogen system (London: Academic Press)

2. Alefeld G and Völkl J 1978 Hydrogen in metals I, II (Berlin: Springer-Verlag)

3. Moy R 2003 Nature 30147

4. Schlapbach L and Züttel A 2001 Nature $\mathbf{4 1 4} 353$

5. Mckee J M 1991 Hydrogen gas sensor and method of manufacture (US Patent 5012672)

6. David L 1984 Handbook of batteries and fuel cells (New York: McGraw-Hill)

7. Zhong W and Tomanek D 1993 Nature 362435

8. Edlund D J and Pledger W A 1993 J. Membr. Sci. 77255

9. Lopez N and Norskov J K 2001 Surf. Sci. 47759

10. Bhatia B and Sholl D S 2005 Phys. Rev. B72 224302

11. Khanuja M, Varandhani D and Mehta B R 2007 Appl. Phys. Lett. 91253121

12. Rodriguez J A and Goodman D W 1992 Science 257897

13. Gauthier Y, Schmid M, Padovani S, Lundgren E, Buš V, Kresse G, Redinger J and Varga P 1994 Phys. Rev. Lett. 87 036103-1

14. Kamakoti P, Morreale B D, Ciocco M V, Howard B H, Killmeyer R P, Cugini A V and Sholl D S 2005 Science 307569

15. McKinley D 1969 US Patent No. 3439474

16. Cheng Y, Peña M, Fierro J, Hui D and Yeung K 2002 J. Membr. Sci. 204329

17. Knapton A 1977 Plat. Metal. Rev. 2144

18. Khanuja M, Mehta B R and Shivaprasad S M 2008 Thin Soild Films 5165435

19. Andersen T H, Bech L, Li Z, Hoffmann S V and Onsgaard J 2004 Surf. Sci. 559111

20. Aruna I, Mehta B R, Malhotra L K and Shivaprasad S M $2004 A d v$. Mater. 16169

21. Abrikosov I A, Olovsson W and Johansson B 2001 Phys. Rev. Lett. 87 176403-1 